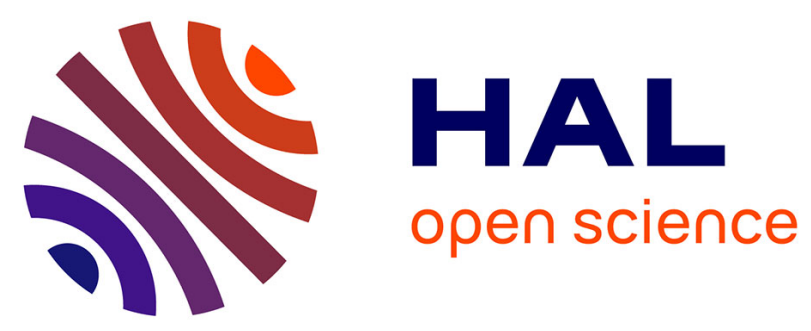

\title{
Mesostructured silica from amino acid-based surfactant formulations and sodium silicate at neutral $\mathrm{pH}$
}

Bejoy Thomas, Niki Baccile, Sylvie Masse, Caroline Rondel, Isabelle Alric, Romain Valentin, Zephirin Mouloungui, Florence Babonneau, Thibaud

Coradin

\section{To cite this version:}

Bejoy Thomas, Niki Baccile, Sylvie Masse, Caroline Rondel, Isabelle Alric, et al.. Mesostructured silica from amino acid-based surfactant formulations and sodium silicate at neutral pH. Journal of Sol-Gel Science and Technology, 2011, 58 (1), pp.170-174. 10.1007/s10971-010-2372-9 . hal-02292406

\section{HAL Id: hal-02292406 \\ https://hal.sorbonne-universite.fr/hal-02292406}

Submitted on 14 Nov 2019

HAL is a multi-disciplinary open access archive for the deposit and dissemination of scientific research documents, whether they are published or not. The documents may come from teaching and research institutions in France or abroad, or from public or private research centers.
L'archive ouverte pluridisciplinaire HAL, est destinée au dépôt et à la diffusion de documents scientifiques de niveau recherche, publiés ou non, émanant des établissements d'enseignement et de recherche français ou étrangers, des laboratoires publics ou privés. 


\section{Mesostructured silica from amino acid-based surfactant}

\section{formulations and sodium silicate at neutral pH}

Bejoy Thomas, ${ }^{[a]}$ Niki Baccile, ${ }^{[a]}$ Sylvie Masse, ${ }^{[a]}$ Caroline Rondel,,${ }^{[b]}$ Isabelle Alric, ${ }^{[b]}$ Romain

Valentin, ${ }^{[b]}$ Zéphirin Mouloungui, ${ }^{[b]}$ Florence Babonneau, ${ }^{[a]}$ and Thibaud Coradin*[a]

${ }^{a}$ UPMC Univ Paris 06; CNRS, Chimie de la Matière Condensée de Paris, Collège de France, 11 place

Marcellin Berthelot, 75005 Paris, France.

${ }^{b}$ Laboratoire de Chimie Agro-Industrielle, 118 route de Narbonne, F-31400 Toulouse, France.

* Corresponding author

Dr. Thibaud Coradin,

University Pierre et Marie Curie - Univ. Paris 06,

CNRS, Laboratoire de Chimie de la Matière Condensée de Paris,

Collège de France, 11 place Marcellin Berthelot,

75005 Paris, France.

Fax : (+33)144271443

E-mail: thibaud.coradin@upmc.fr 


\begin{abstract}
We report on the synthesis of hybrid mesostructured silica from aqueous solutions of $\mathrm{C}_{12}$-Glutamic acid and $\mathrm{C}_{12}$-Lecucine based surfactant formulations with sodium silicate under neutral $\mathrm{pH}$ and atmospheric conditions. The approach shows the challenging task of organizing silica from entirely sustainable sources under environmentally benign conditions.
\end{abstract}

\title{
Keywords
}

Biosurfactants; Mesostructured materials; Green Chemistry; Silica

\section{Introduction}

Silica-based mesoporous materials with extremely high surface areas and ordered mesostructures $[1,2]$ are of great interest to scientists in many disciplines, with potential applications as catalysts, biocatalysts, separation media and drug delivery [3]. A vast majority of such synthetic approaches use a silicon alkoxide source and a synthetic/petroleum-based surfactant as structure directing agent (SDA) [2]. Moreover, some of these materials are synthesized under extreme $\mathrm{pH}$ conditions. From a sustainable point of view, the main limitations for these approaches are the cost of the reactants, requirement of catalysts and/or alcoholic media and potential environmental impact of these molecules [4]. Two approaches can be used to make the process more environment-friendly: use of (1) aqueous silicates as the silica source and (2) surfactants with limited environmental impact [4a]. A large number of reports describe the use of low-cost soluble silicates to make mesostructured silica $[1 \mathrm{~g}, 5,6]$, but involving synthetic surfactants as SDAs. However, more than 1000 molecules of different origins were reported as biosurfactants either because they are extracted from plants or microbial medium or because they are produced from natural molecules like saccharides, aminoacids or fatty acids [7]. The main advantage of natural amphiphiles is their limited toxicity due to their easy biodegradation. However, there are only 
limited reported attempts to use biosurfactants as SDAs in the synthesis of ordered mesostructures [8] and, to our knowledge, only one uses sodium silicate solutions as the source of inorganic precursors [9]. One of the limitations in using biosurfactants is that they are often obtained as mixtures whose purification increases both the cost and the environmental impact. This is not a problem when they are used as such, within formulations. However, it represents a real challenge if one wishes to use them as SDA because each of the components may interact differently with inorganic precursors, preventing a suitable organization of the porous network. Until now, this point has not been addressed in the literature.

The search for special surfactants is stimulated from the fast growing demands for green approaches for material synthesis. The driving force is the growing awareness that we are responsible for our environment and an increasing concern about our own health. Amino acid based surfactants such as sodium lauroyil sarcosinate and sodium cocoyl glutamate were commercially produced and are important ingredients for medical non-alkaline bar cleansers. Indeed, these surfactants are regarded as having very low toxicity, antimicrobial activity, are less irritating to skin, and are highly biodegradable in natural environments [10]. With the aim of using natural surfactant formulations as structuring directing agent, we selected two surfactants derived from glutamic acid and leucine for the synthesis of mesostructured silica from sodium silicate under fully benign conditions.

\section{Experimental section}

\subsection{Materials}

L-Glutamic acid (>99\%, Sigma), L-leucine (>99\%, Sigma), dodecanoyl chloride (99.9\%, Aldrich), sodium hydroxide $(\mathrm{NaOH}, 99.9 \%$, Aldrich), hydrochloric acid (HCl, 37\%, Merck), sodium silicate $\left(\mathrm{SiO}_{2} 27 \%, \mathrm{Na}_{2} \mathrm{O} 10 \%\right.$, Riedel-de Haën) were used as received.

\subsection{Preparation of surfactant formulation}


A long chain fatty acyl group is introduced to the nitrogen part of amino acid by using an acid chloride. This Schotten-Baumann method is a classical and useful way to synthesise $N$-acylamino acids in good yields [11a]. In the present approach the amino acids were treated with an excess of dodecanoyl chloride in alkaline aqueous medium, resulting in sodium salts of a $N^{\alpha}$-lauroylamino acid and fatty acid mixture (ca. $50 \mathrm{w} \%)$ (Scheme 1) [11b].

\section{Scheme 1}

\subsection{Preparation and characterization of hybrid-silica based materials}

In a typical synthesis experiment, $50 \mathrm{~mL}$ of millimolar sodium silicate solution, neutralized to $\mathrm{pH} 7 \mathrm{by}$ dilute hydrochloric acid addition was added slowly to $50 \mathrm{~mL}$ of the surfactant solution. Details about the combination of various concentrations of sodium silicate and surfactant employed in the investigation are described in the supporting informations (SI-1). The mixture was stirred for $72 \mathrm{~h}$ at room temperature and white solid was recovered by filtration or by centrifugation at $10,000 \mathrm{rpm}$. The product was washed several times with deionised water and air-dried.

Powder X-ray diffraction study was performed on Bruker D8 Advance diffractometer using Cu$\mathrm{K} \alpha(1.54056 \AA$ A $)$ radiation. Scanning electron microscopy (SEM) images were obtained using a JEOL JSM-5510LV instrument operating at $20 \mathrm{kV}$. Transmission electron microscopy (TEM) images were obtained with JEOL 1011 equipped with a numeric camera, operating at a low accelerating voltage (60 $\mathrm{kV}$ ) to avoid sample degradation under the intense electron beam.

\section{Results and discussion}

The amino acid based surfactant compositions typically represent mixtures of amphiphilic anionic surfactants, both contributing to the properties of a typical formulation. Measurements of surface-active properties such as critical micelle concentration (CMC), surface tension at the CMC (ST) and foaming 
capacity (FC) demonstrate that they possess desired properties of surfactants, which are comparable to petroleum-based surfactants such as cetyltrimethylammonium bromide (CTAB) (Table 1).

\section{Table 1}

In a first step, the $\mathrm{C}_{12}$-glutamic acid based surfactant formulation at $\mathrm{CMC}$ was mixed at room temperature with a diluted sodium silicate solution at neutral $\mathrm{pH}$ (see experimental section). Based on typical mesoporous silica preparation, [2] the [Si]/[surfactant] ratio was adjusted to 10 . The XRD pattern of the recovered powder is shown on Fig. 1a, exhibiting a series of diffraction peaks at $2 \theta=2.6^{\circ}, 3.3^{\circ}$, $5.2^{\circ}, 6.5^{\circ}$ and $7.8^{\circ}$. Considering the relative intensity of these peaks, it can be proposed that two lamellar organization $\mathrm{L}_{1}$ and $\mathrm{L}_{2}$ co-exist within the hybrid materials with respective wall-to-wall inter distance $d$ of $3.4 \mathrm{~nm}$ and $2.8 \mathrm{~nm}$, respectively. It is worth noting that the first value is very close to interbasal distance obtained for CTAB-based lamellar silica (MCM-50). When observed by SEM, the resulting materials consist of micrometer-size platelets (Fig 2a) while TEM indicates the presence of lamellar structure (Fig 3a). Noticeably, the wall-to-wall distance obtained from TEM was $c a .3 \mathrm{~nm}$, in good agreement with the XRD attribution.

\section{Figure 1}

Under similar experimental conditions as for the $\mathrm{C}_{12}$-Glutamic acid/silica system, the $\mathrm{C}_{12}$ Leucine surfactant formulation also gave rise to a multiphase mesostructured material (Fig. 1b). In this case, it was possible to identify a lamellar structure L'2 whose interplanar distance, $d=2.8 \mathrm{~nm}$, is comparable to the $\mathrm{L}_{2}$ phase of the $\mathrm{C}_{12}$-Glutamic acid/silica sample. In addition, the $\mathrm{L}_{2}$ seems to co-exist with a second phase which is identified by the peaks labeled as $C$ at $2 \theta=4.6^{\circ}$ and $5.3^{\circ}$. After several attempts, we could tentatively attribute these peaks to the 211 and 220 reflections of a Ia3d cubic mesophase. The corresponding calculated cell parameter $a$ is $4.8 \mathrm{~nm}$. The peak attribution could be confirmed by TEM observations, which show the coexistence of lamellar and cubic mesostructures 
within the silica materials (Fig 3b). Additional SEM experiments show a layered solid, which also suggests a long-range lamellar organization (Fig. 2b).

\section{Figure 2}

Noticeably, the $d$ parameter for CTAB-based MCM-50 lamellar silica was reported to be $c a .3$ $\mathrm{nm}$, [1] supporting our attribution of the lamellar phase for both samples. In contrast, the typical $a$ parameter for the CTAB-based MCM-48 cubic phase is in the 8.5-9 nm range, [1] significantly higher than the present investigation value, suggesting that another component of the formulation is involved in the templating process.

\section{Figure 3}

In order to substantiate the influence of amino acid based surfactant formulation on the formation of mesostructured silica, we have performed blank experiments in the absence of surfactants, which did not lead to the precipitation of silica even after two weeks. Trials with dodecanoyl chloride, dodecanoic acid (lauric acid) or a 1:1 mixture of the $\mathrm{C}_{12}$-Glutamic acid formulation and lauric acid as structure directing agents have led to the precipitation of disordered silica materials in few days.

It is also worth noting that neither the $\mathrm{C}_{12}$-Glutamic acid/silica nor the $\mathrm{C}_{12}$-Leucine/silica mesostructured materials maintained any level of organization after calcination at $600^{\circ} \mathrm{C}$, as checked by XRD and TEM. This is in good agreement with the fact that lamellar silica mesostructures tend to collapse upon surfactant withdrawing [1]. However, SEM indicates that a lamellar morphology was still present after SDA removal (Fig 2c,2d).

It is very important to emphasize that the combination of amino acid-based surfactant formulations, sodium silicate and neutral $\mathrm{pH}$ conditions made the synthesis of these materials a harsh task. In fact, in order to achieve the reaction at $\mathrm{pH}=7$ to avoid the degradation of the surfactant via 
hydrolysis reactions, sodium silicate solution could only be used at concentrations lower than $c a$. 80 mM. Moreover, any attempt to obtain a structured solid at sodium silicate concentrations higher than $c a$. $25 \mathrm{mM}$ systematically failed. In these conditions, only a low amount of material could be recovered. In addition, due to the presence of a formulation, exact calculations based on molarity are obviously approximate.

\section{Conclusions}

Overall, these data suggest that formulations based on acylated amino acids can be used as structure directing agents to form mesostructured silica in the presence of aqueous sources of silica, in solventfree conditions, at neutral $\mathrm{pH}$ and room temperature. However, a mixture of meso-organizations is obtained, probably due to the initial presence of several surface-active agents in the formulation. Moreover, these organizations are obtained only in a very narrow range of compositions, indicating the strong influence of silica-surfactant interactions on the structuring process. Nevertheless, these results demonstrate that extensive purification of surfactants, a step which often has a strong influence on processing cost and environmental impact [4], is not always required, opening the possibility to use a wide variety of natural extracts and commercial formulations as structure directing agents for the formation of mesostructured materials under benign conditions.

\section{Acknowledgements}

B. T. thanks the Conseil Régional d'Ile-de-France for his postdoctoral fellowship. M. Selmane and G. Mosser (LCMCP) are thanked for their help in XRD and TEM experiments. This project was supported by an AIC CPDD-RDR1 from CNRS/INRA.

\section{References}


[1] a) Kresge CT, Leonowicz ME, W. Roth WJ, Vartuli JC, Beck JS (1992) Nature 359: 710-712; b) Zhao DY, Feng J, Huo Q, Melosh N, Fredrickson GH, Chmelka BF, Stucky GD (1998) Science 279: 548-552; c) Templin M, Franck A, Du Chesne A, Leist H, Zhang Y, Ulrich R, Schädler V, Wiesner U (1997) Science 278:1795-1798; d) Kim, SS Zhang W, Pinnavaia TJ (1998) Science 282: $1302-1305$.

[2] a) Davis ME (2002) Nature $417: 813-821$; b) Soler-Illia GJ de AA, Sanchez C, Lebeau B, Patarin J (2002) Chem Rev 102 :4093-4138; c)Meynen V, Cool P, Vansant EF (2009) Microporous Mesoporous Mater 125: 170-223.

[3] a) Taguchi A, Schüth F (2005) Microporous Mesoporous Mater 77: 1-45; b) Yiu HHP, Wright PA (2005) J Mater Chem 15 :3690-3700; c) Vallet-Regi M, Balas F, Arcos D (2007) Angew. Chem. Int. Ed. 46 :7548-7558.

[4] a) Baccile N, Babonneau F, Thomas B, Coradin T (2009) J Mater Chem 19: 8537-8559; b) Jeswiet J, Hauschild M (2005) Mater Design 26 : 629-634; c) Eckelman MJ, Zimmerman JB, Anastas PT (2008) J Industr Ecol 12 : 316-328; d) Knight P, Jenkins JO (2009) J Clean Prod 17 : 549-558.

[5] a) Jo C, Kim K, Ryoo R (2009) Microporous Mesoporous Mater 124 : 45-51; b) Kato M, Shigeno T, Kimura T, Kuroda K (2005) Chem Mater 17 : 6416-6421; c) Kim JM, Stucky GD (2000) Chem Commun 1159-1160; d) Boissiere C, Larbot A, Prouzet E (2000) Chem Mater 12 : 1937-1940.

[6] a) Pauly TR, Petkov V, Liu Y, Billinge SJL, Pinnavaia TJ (2002) J Am Chem Soc 124 : 97-103; b) Liu Y, Karkamkar A, Pinnavaia TJ (2001) Chem Commun 1822-1823; c) Tanev PT, Pinnavaia TJ (1996) Chem Mater 8 : 2068-2079.

[7] a) Dembitsky VM (2004) Lipids 39 : 933-953 ; b) Dembitsky VM (2005) Lipids 40 : 219 -248 ; c) von Rybinski W, Hill K (1998) Angew Chem Int Ed 37 : 1328-1345.

[8] a) Rabatic BM, Pralle MU, Tew GN, Stupp SI (2003) Chem Mater 15 : 1249-1255; b) Mureseanu M, Galarneau A, Renard G, Fajula F (2005) Langmuir 21 : 4648-4655; c) Takahashi S, Ikkai Y, Sakamoto K, Abreu CR, Aramaki K (2009) J Colloid Interf Sci 335 : 70-76; d) Boffa V, Perrone 
DG, Montoneri E, Magnacca G, Bertinetti L, Garlasco L, Mendichi R (2010) ChemSusChem 3 : $445-452$.

[9] Coradin T, Roux C, Livage J (2002) J Mater Chem 12 : 1242-1244.

[10] (a) Infante MR, Perez L, Pinazo A, Clapes AP, Moran MC, Angelet M, Garcia MT, Vinardell MP (2004) Comptes Rendus Chimie 7 : 583-592 ; (b) Hausman M, Menting K, Reickert H, Ring H, Weisse J, Zinser J (2004) SOFW J 10 : 22-28.

[11] (a) Smith MB, March J (2001) Advanced Organic Chemistry: Reactions, Mechanisms, and Structure, Wiley-Interscience, New York ; (b) Rondel C, Alric I, Mouloungui Z, Blanco JF and Silvestre F (2009) J Surfact Deterg 12 : 269-275. 
Table 1. Critical micelle concentration (CMC), surface tension at the CMC (ST) and foaming capacity (FC) of formulations based on $N^{\alpha}$-acylamino acid and acylated peptide. Values for CTAB are also provided as reference.

\begin{tabular}{llll}
\hline Surfactant & $\mathrm{CMC}^{\mathrm{a}}\left(\mathrm{mg} . \mathrm{L}^{-1}\right)$ & $\mathrm{ST}^{\mathrm{b}}\left(\mathrm{mN} . \mathrm{m}^{-1}\right)$ & $\mathrm{FC}^{\mathrm{c}}(\%)$ \\
\hline $\mathrm{C}_{12}$-Glutamic acid & 800 & 38.5 & 120 \\
$\mathrm{C}_{12}$-Leucine & 310 & 30.0 & 200 \\
CTAB & 140 & 31.0 & 200 \\
\hline
\end{tabular}

${ }^{\mathrm{a}} \pm 50$ mg.L- $1,{ }^{\mathrm{b}} \pm 0.5 \mathrm{mN} \cdot \mathrm{m}-1,{ }^{\mathrm{c}} \pm 5 \%$ 


\section{Figure captions}

Scheme 1. Two competitive reactions (acylation and hydrolysis of acid chloride) occurring during the preparation the surfactant formulation from amino acid and acid chloride. $\mathrm{C}_{12}$-Glutamic acid: $\mathrm{R}^{\prime}=\mathrm{C}_{12}$; $\mathrm{R}=\mathrm{CH}_{2} \mathrm{CH}_{2} \mathrm{COOH} ; \mathrm{C}_{12}$-Leucine: $\mathrm{R}^{\prime}=\mathrm{C}_{12} ; \mathrm{R}=\mathrm{CH}_{2} \mathrm{CH}\left(\mathrm{CH}_{3}\right)_{2}$.

Figure 1. (a) XRD pattern of (a) C12-Glutamic acid/silica (Sample B, see supporting information) and (b) C12-Leucine/silica (Sample G, see supporting information) materials, (C = cubic; L = lamellar).

Figure 2. SEM images of (a) $\mathrm{C}_{12}$-Glutamic acid/silica, (b) $\mathrm{C}_{12}$-Leucine/silica as-prepared and (c) $\mathrm{C}_{12^{-}}$ Glutamic acid/silica, (d) $\mathrm{C}_{12}$-Leucine/silica after calcination (scale bar $\left.=5 \mu \mathrm{m}\right)$.

Figure 3. TEM images of (a) $\mathrm{C}_{12}$-Glutamic acid/silica (scale bar $=20 \mathrm{~nm}$ ), (b) $\mathrm{C}_{12}$-Leucine/silica (scale bar $=50 \mathrm{~nm}$, insert scale bar $=20 \mathrm{~nm})$. 


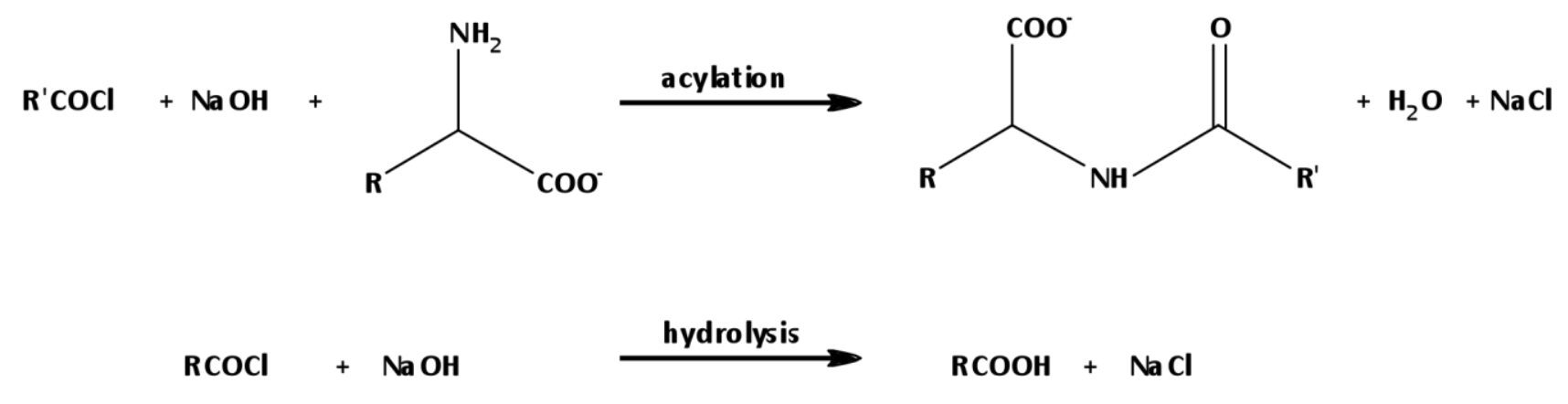

Scheme 1 

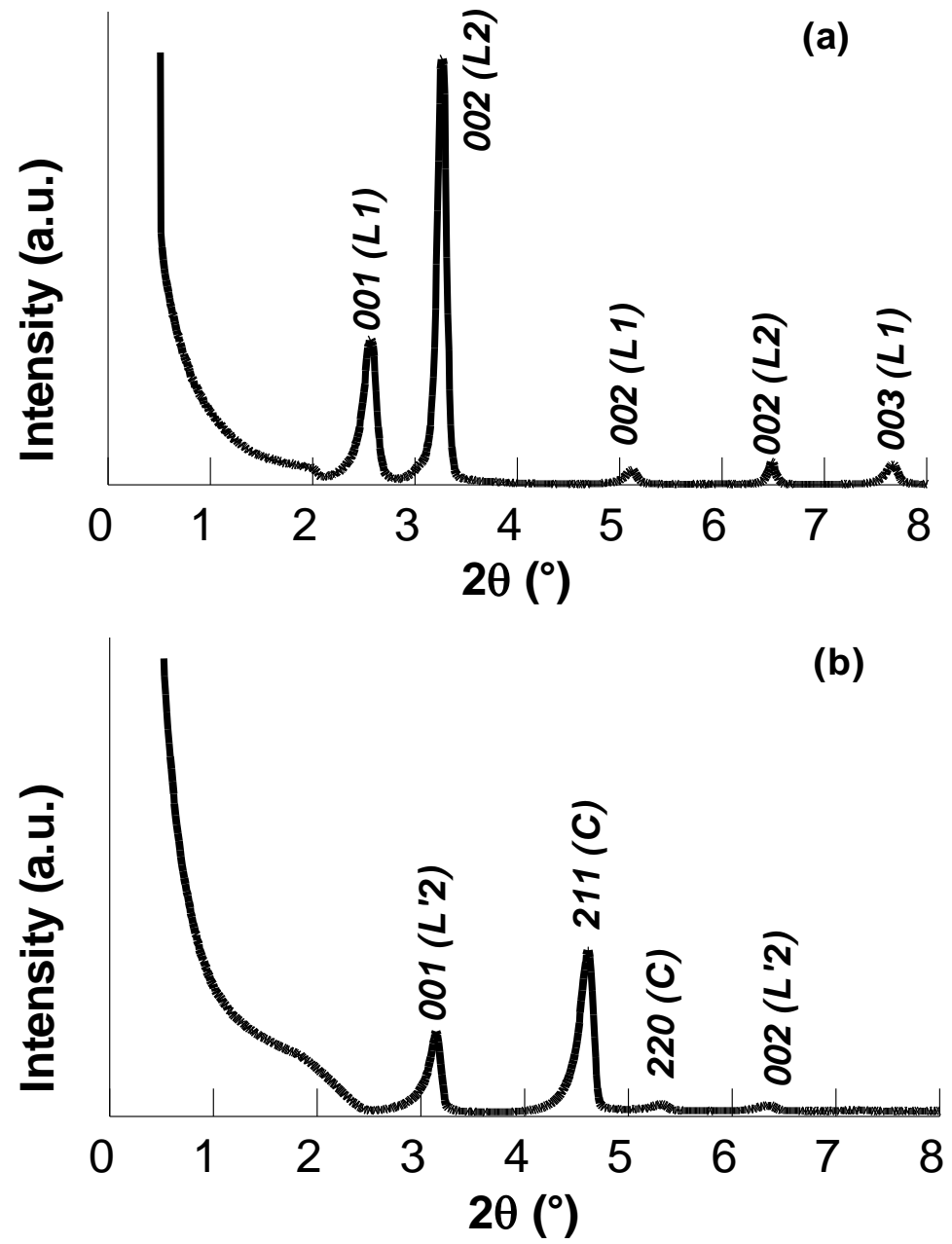

Figure 1 


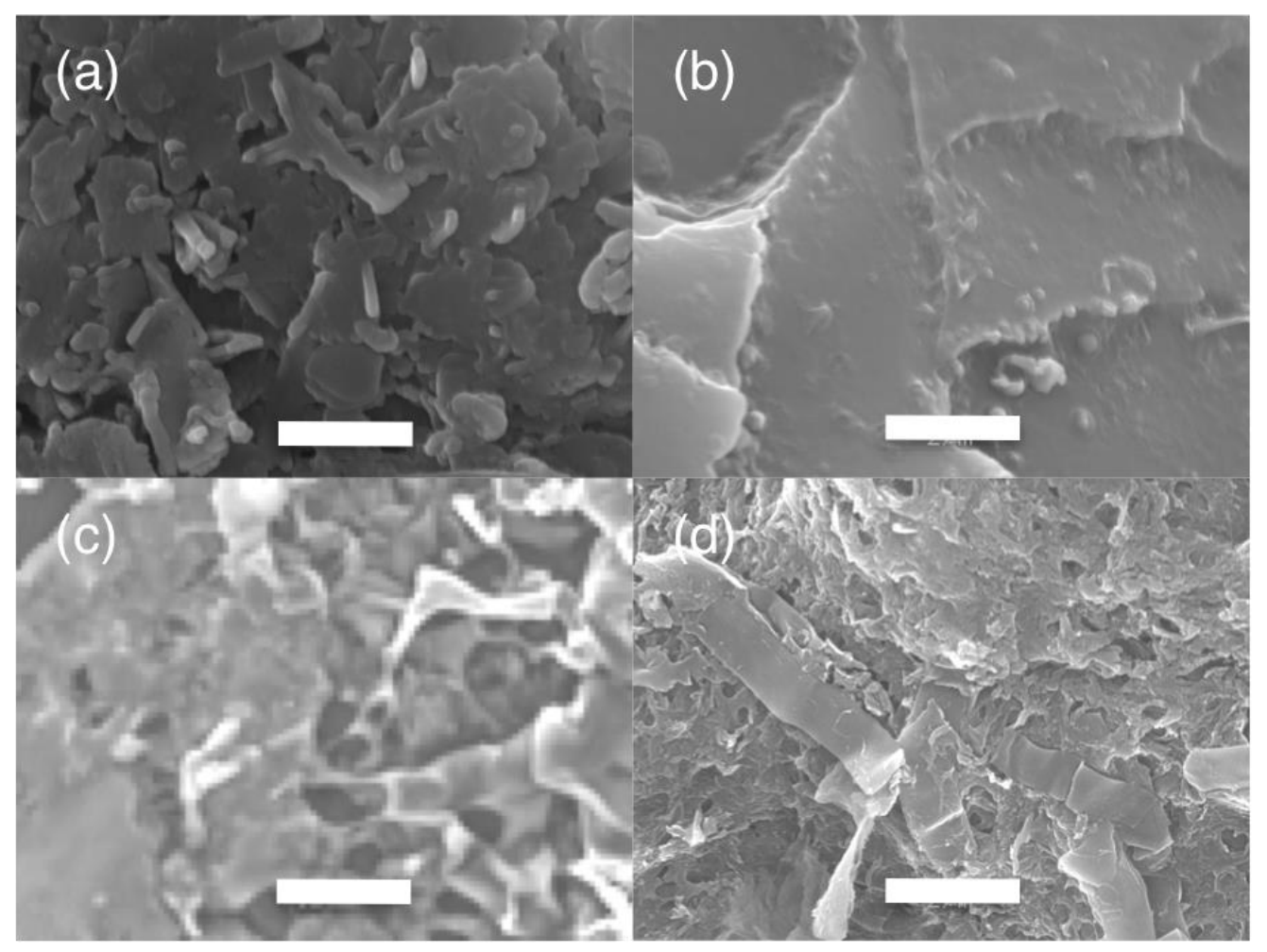

Figure 2 


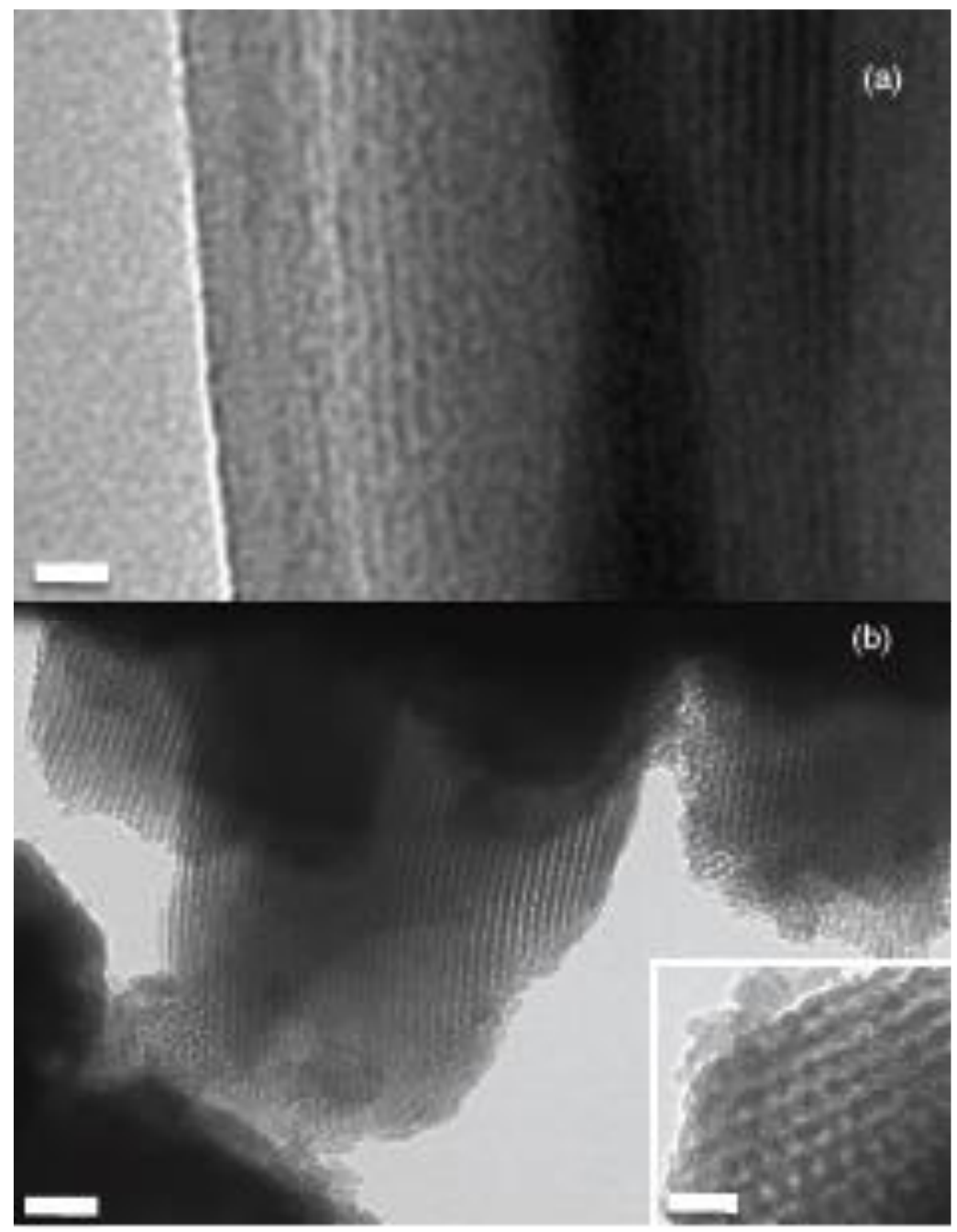

Figure 3 


\section{Supplementary informations}

\section{Mesostructured silica from amino acid-based surfactant formulations and sodium silicate at neutral pH}

Bejoy Thomas, Niki Baccile, Sylvie Masse, Caroline Rondel, Isabelle Alric, Romain Valentin, Zéphirin Mouloungui, Florence Babonneau, and Thibaud Coradin

\begin{tabular}{|c|c|c|c|c|c|}
\hline \multirow[t]{2}{*}{ Sample } & \multirow[t]{2}{*}{$\begin{array}{l}{[\mathrm{Si}]:[\text { surfactant }]} \\
\text { molar ratio }^{\mathrm{a}}\end{array}$} & \multirow[t]{2}{*}{$\begin{array}{l}\text { Concentration of } \\
\text { silicate }(\mathrm{mM})\end{array}$} & \multicolumn{2}{|c|}{$\begin{array}{l}\text { Concentration of surfactant } \\
(\mathrm{g} / \mathrm{L})\end{array}$} & \multirow[t]{2}{*}{$\begin{array}{l}\text { Nature of } \\
\text { product }\end{array}$} \\
\hline & & & $\begin{array}{l}\mathrm{C}_{12} \text {-glutamic acid } \\
\text { formulation }\end{array}$ & $\begin{array}{l}\mathrm{C}_{12} \text {-leucine } \\
\text { formulation }\end{array}$ & \\
\hline $\mathrm{A}$ & 5 & 13.9 & 0.80 & - & Structured \\
\hline B & 10 & 27.9 & 0.80 & - & Structured \\
\hline $\mathrm{C}$ & 10 & 41.7 & 1.20 & - & Non-structured \\
\hline $\mathrm{D}$ & 10 & 55.6 & 1.59 & - & Non-structured \\
\hline $\mathrm{E}$ & 10 & 69.5 & 1.99 & - & Non-structured \\
\hline $\mathrm{F}$ & 10 & 80.0 & 2.29 & - & Non-structured \\
\hline $\mathrm{G}$ & 10 & 22.2 & - & 0.62 & Structured \\
\hline $\mathrm{H}$ & 10 & 44.4 & - & 1.24 & Non-structured \\
\hline I & 10 & 88.8 & - & 2.48 & Non-structured \\
\hline
\end{tabular}

${ }^{\text {a }}$ Considering the $\mathrm{C}_{12}$-glutamic acid and $\mathrm{C}_{12}$-leucine based formulations a 50:50 wt $\%$ mixture of the aminoacid amide and sodium salt of lauric acid, the molar concentration of surfactants were calculated from the average molecular weight of the amide and sodium laurate.

SI-1: Experimental conditions evaluated for mesostrctured silica formation in the presence of $\mathrm{C}_{12}-$ glutamic acid and $\mathrm{C}_{12}$-leucine surfactant formulations. 